\title{
Margaret McCartney: Why is it so hard to do what we know works?
}

\author{
Margaret McCartney general practitioner
}

Glasgow

It's hiding in plain sight. Poor people live less long than those who are rich, ${ }^{1}$ and people with a learning disability are more likely to die sooner than people without. ${ }^{2}$ GPs have been urged to respond to this in the way the contract knows best: by offering health checks and a checklist of items to be ticked.

In Scotland the Keep Well programme, aimed at people in deprived areas, has demonstrated only minimal or marginal benefits but is still used in some areas.

Health checks for people with learning disabilities often detect symptomatic conditions. This is itself a concern, as doing health checks once a year may generate a stock delay in a system where people or carers may wait for an invitation rather than having prompt attention to symptomatic issues. And, while clinical review is often a case of simply good practice, health checks for people with learning disabilities can identify unmet needs, but they haven't been shown to reduce mortality and morbidity. ${ }^{4}$

Can medicine correct these inequalities? The ASSIGN risk calculator, for example, has been developed to consider deprivation as a risk factor for cardiovascular disease. ${ }^{5}$ It means that we're effectively treating poverty with statins. The real world benefit of encouraging lifestyle interventions has not been demonstrated, ${ }^{6}$ and the effects of austerity may have a far larger role in determining mortality.

Meanwhile, people with learning disabilities are more likely to have epilepsy and are more likely to die earlier if they do. ${ }^{8}$ This is an area with high potential for improvement, yet the lack of randomised controlled trials on the best treatments for this group of people has been well noted for years. ${ }^{9}$ In 2015 a Cochrane review found that "very few high quality studies" had been performed among this group despite as many as $44 \%$ of people with a learning disability having epilepsy. ${ }^{10}$

We have premature mortality—but not enough high quality evidence to know whether what we're recommending at health checks will improve outcomes

We have premature mortality—but not enough high quality evidence to know whether what we're recommending at health checks for people with learning disabilities and epilepsy will improve outcomes.

There's little doubt that health checks targeted at people living in deprived areas are a medical fig leaf attempting to cover austerity economics. It's hardly feasible that health checks will square the circle of deprivation. The premature mortality associated with deprivation has complicated causes, and it's likely to have complicated answers. Repeating known failures will not help.

We're fiddling with health checks while people die. For people with learning disabilities, the ongoing deficit in knowledge on best treatments for epilepsy-despite the risk of sudden death-is needless. There's no lack of opportunity to obtain better knowledge.

Stopping things that don't work, and acting on the knowledge that we don't know what does work: why is that so difficult?

Competing interests: See www.bmj.com/about-bmj/freelancecontributors/margaret-mccartney.

Provenance and peer review: Commissioned; not externally peer reviewed.

Follow Margaret on Twitter, @mgtmccartney

Thomas B, Dorling D, Smith GD. Inequalities in premature mortality in Britain: observational study from 1921 to 2007. BMJ 2010;356:c3639. doi:10.1136/bmj.c3639 pmid:20650979. 2 Heslop P, Blair P, Fleming P, Hoghton M, Marriott A, Russ L. Confidential enquiry into premature deaths of people with learning disabilities (CIPLOD). 2013. www.bristol.ac.uk media-library/sites/cipold/migrated/documents/fullfinalreport.pdf.

3 Geue C, Lewsey JD, MacKay DF, et al. Scottish Keep Well health check programme: an interrupted time series analysis. J Epidemiol Community Health 2016;356:924-9. http:// interrupted time series analysis. J Epidemiol Community Health 2016;356:924-9. http://
eprints.gla.ac.uk/118710/7/118710.pdf. doi:10.1136/jech-2015-206926 pmid:27072868. Robertson J, Roberts H, Emerson E. Improving Health and Lives; Learning Disabilities Observatory. Health Checks for People with Learning Disabilities: A Systematic Review of Evidence. https://www.improvinghealthandlives.org.uk/uploads/doc/vid_7646_IHAL201004HealthChecksSystemticReview.pdf.

5 ASSIGN. www.assign-score.com/reference

6 Jørgensen T, Jacobsen RK, Toft U, Aadahl M, Glümer C, Pisinger C. Effect of screening and lifestyle counselling on incidence of ischaemic heart disease in general population: Inter99 randomised trial. BMJ 2014;356:g3617. doi:10.1136/bmj.g3617 pmid:24912589.

7 Hiam L, Dorling D, Harrison D, McKee M. What caused the spike in mortality in England and Wales in January 2015? J R Soc Med 2017;141076817693600. doi:10.1177/ 0141076817693600 . pmid:28208024. 
8 Robertson J, Hatton C, Emerson E, Baines S. Mortality in people with intellectual disabilities and epilepsy: A systematic review. Seizure 2015;356:123-33. doi:10.1016/..seizure.2015. 04.004 pmid:26076855.

9 Ring H, Zia A, Bateman N, Williams E, Lindeman S, Himlok K. How is epilepsy treated in people with a learning disability? A retrospective observational study of 183 individuals. Seizure 2009;356:264-8. doi:10.1016/j.seizure.2008.10.009 pmid:19046901.
10 Jackson CF, Makin SM, Marson AG, Kerr M. Pharmacological interventions for epilepsy in people with intellectual disabilities. Cochrane Database Syst Rev 2015;356:CD005399.pmid:26333428.

Published by the BMJ Publishing Group Limited. For permission to use (where not already granted under a licence) please go to http://group.bmj.com/group/rights-licensing/ permissions 